\title{
AVALIAÇÃO DE PROGRAMAS DE RESIDÊNCIA MULTIPROFISSIONAL EM SAÚDE DA FAMÍLIA POR INDICADORES
}

\author{
INDICATOR-BASED EVALUATION OF MULTI-PROFESSIONAL RESIDENCY PROGRAMS \\ IN FAMILY HEALTH
}

\section{EVALUACIÓN DE PROGRAMAS DE RESIDENCIA MULTIPROFESIONAL EN SALUD DE LA FAMILIA POR INDICADORES}

\author{
Maristela Inês Osawa Vasconcelos ${ }^{1}$ \\ Francisca Lopes de Souza ${ }^{2}$ \\ Geison Vasconcelos Lira ${ }^{3}$ \\ Maria Socorro de Araújo Dias ${ }^{4}$ \\ Geórgia Sibele Nogueira da Silva ${ }^{5}$
}

Resumo A Residência Multiprofissional em Saúde da Família caracteriza-se como formação em serviço que promove aproximação da realidade do Sistema Único de Saúde. Apesar de empiricamente existir a constatação de resultados positivos na atuação profissional, não há um modelo de avaliação dos resultados. Este artigo detém-se na descrição e análise do processo de adaptação e validação de estruturas essenciais de avaliação e seus respectivos indicadores para a construção de modelos de autoavaliação para programas de residências multiprofissionais em saúde da família. Em oficina, foram apresentados instrumentos aos especialistas, que deveriam fazer considerações sobre eles. As observações foram analisadas e as consideradas pertinentes com os objetivos de avaliação foram acatadas. A construção e a validação de indicadores de autoavaliação de programas de Residência Multiprofissional em Saúde da Família, ora realizadas, sinalizam a relevância de uma proposta que supere as avaliações 'tradicionais' e se torne um processo tão inventivo quanto se deseja às residências.

Palavras-chave avaliação de programas e projetos de saúde; internato e residência; programa saúde da família.
Abstract The Multidisciplinary Residency in Family Health is characterized as in-service training that promotes an approximation to the reality of the Unified Health System. Although empirically it is found that there are positive results in the professional activity, there is no model to value results. This article dwells on the description and analysis of the process of adapting and validating essential structures of evaluation and their respective indicators for the construction of self-assessment models for programs aimed at multidisciplinary residency in family health. During the workshop, tools were presented to experts who were asked to make considerations about them. Their observations were analyzed and those considered relevant to the evaluation objectives accepted. The construction and validation of self-evaluation indicators for Multidisciplinary Residency in Family Health programs that were conducted signal the relevance of a proposal that goes beyond the 'traditional' ratings and becomes a process that is as inventive as desired for the residencies.

Keywords evaluation of health programs and projects; internship and residency; family health program. 


\section{Introdução}

A Residência Multiprofissional em Saúde da Família (RMSF) é uma modalidade de formação em pós-graduação que vem sendo desenvolvida para aproximar a formação profissional em saúde da realidade social e do trabalho no contexto do Sistema Único de Saúde (SUS) (Parente, Dias e Chagas, 2000). Apresenta como principal desafio a superação de limitações decorrentes da formação original dos profissionais nos cursos regulares de graduação, contribuindo significativamente para uma atuação contextualizada e comprometida com o SUS, reconhecendo, ainda, que as diferentes categorias profissionais da saúde tendem a reproduzir uma visão fragmentada do fenômeno saúde. A RMSF opera a partir de um novo paradigma, promovendo uma visão sistêmica e uma ação baseada na colaboração interprofissional (Morin, 2000).

Dado o destaque que os programas de RMSF vêm assumindo como estratégia de formação para o SUS, considerando, por exemplo, o aporte de recursos financeiros destinados a tais programas pelo Ministério da Saúde, no período recente se faz necessária a construção de modelos de avaliação que indiquem a efetividade dessa modalidade de educação.

O exposto nos permite inferir que a RMSF é uma das estratégias de educação permanente que tem se destacado como fator de mudança na formação de profissionais para o SUS, com influência na assistência, no ensino e na pesquisa e tendo como lócus o processo de trabalho (Martins Junior et al., 2008).

A contribuição da RMSF na formação de profissionais é percebida de maneira empírica, pois ainda não há uma sistemática de avaliação da sua eficácia. Acreditamos que a avaliação da RMSF pode nos dar subsídios para o direcionamento da política de educação na saúde.

O fato de não existir uma política específica para avaliar a pós-graduação lato sensu permite que as instituições tenham maior autonomia na proposição dos programas de seus cursos de especialização; no entanto, isso acarreta a proliferação de uma variedade de cursos, que na área da saúde muitas vezes não se adequam às políticas de saúde advindas do SUS. O programa de RMSF se classifica como uma pós-graduação lato sensu e também sem um sistema avaliativo em uso. Não se tem indicativos concretos de que os programas pedagógicos atendam às necessidades do Programa Saúde da Família, assim como se a coordenação, o corpo docente e a estrutura física das instalações realmente estão dando conta das necessidades dos discentes e do sistema de saúde.

O presente artigo é resultado de um projeto de pesquisa ${ }^{6}$ que teve como objetivo construir e validar um modelo de avaliação estrutural-sistêmico aplicável em RMSF a partir do referencial elaborado por Lima (2008).

Para dar conta do propósito de construir e validar um modelo de avaliação optou-se por duas estratégias centrais: desenvolver um referencial 
teórico-metodológico de avaliação de cursos de RMSF e criar uma plataforma informatizada para gestão dos processos de avaliação desta residência.

A partir dos resultados dessa fase, pode-se delinear uma proposta de avaliação dos programas de RMSF que contempla três fases: a autoavaliação, a avaliação externa e um sistema de informação para fins de complementação da avaliação do desempenho dos residentes. Cada uma dessas propostas passou por validação de especialistas após elaboração de matrizes.

A segunda estratégia consistiu no desenvolvimento de programas de computador para implementar o processo de avaliação de RMSF após a validação realizada utilizando-se a técnica painel de especialistas.

Para efeito deste artigo, vamos nos deter à descrição e análise do processo de adaptação e validação de estruturas essenciais de avaliação e seus respectivos indicadores para a construção de modelos de autoavaliação para programas de RMSF.

\section{Método e percursos do estudo}

O referencial teórico-metodológico adotado na pesquisa para a construção de um modelo de autoavaliação para programas de RMSF foi o proposto por Lima (2008) - a teoria estrutural-sistêmica. O método preconiza o mapeamento das macroestruturas essenciais de avaliação para posteriormente identificar os níveis das estruturas e subestruturas, até chegar aos indicadores quantitativos e qualitativos. Utilizou-se de pesquisa documental aliada a outras pesquisas exploratórias para identificação das estruturas essenciais de avaliação e seus indicadores, e posterior adaptação da matriz elaborada por Lima (2008) ao objeto da pesquisa e sua validação por especialistas.

\section{Abordagem e tipologia do estudo}

Optou-se por uma pesquisa com abordagem essencialmente qualitativa, do tipo estudo de caso. Para Minayo (2008), pesquisa com abordagem qualitativa é o que se aplica ao estudo da história, das relações, das representações, das crenças, percepções e opiniões.

A pesquisa documental pode ser definida, segundo Gil (2002), como aquela que se utiliza de materiais que ainda não foram analisados ou que podem ser reelaborados de acordo com os objetivos da pesquisa.

O estudo de caso é definido por Yin (2001) como sendo de caso único e de casos múltiplos. Nesta pesquisa, adotou-se o estudo de casos múltiplos, pois, segundo esse autor, quando o mesmo estudo contém mais de um caso único é recomendado utilizar o estudo de casos múltiplos. Yin (2001) subdivide-o em holísticos e incorporados. Os holísticos aplicam-se a situações em que não é possível identificar uma subunidade lógica. Martins (2008) ressalta 
os incorporados, afirmando que são aqueles em que a situação é avaliada a partir de diferentes unidades ou níveis de análise e podem ser atividades (processo de planejamento e processo de implantação, por exemplo). Para efeito desse estudo optou-se pelo estudo de caso múltiplo incorporado.

\section{Cenários e informantes do estudo}

A pesquisa foi realizada tendo como unidades de análise os programas de Sobral e Fortaleza, no estado do Ceará. O programa de residência de Sobral à época da pesquisa finalizava a oitava turma, contando com 209 egressos, e o programa de Fortaleza possuía 66 egressos e iniciava a sua terceira turma.

Na fase de validação da matriz de autoavaliação, pela especificidade da temática avaliação de programas de RMSF, optou-se por um painel de especialistas que contemplasse os dois programas pesquisados. Foram considerados especialistas os docentes, residentes e as coordenações dos dois programas.

Segundo Struchiner, Ricciardi e Vetromille (1998), o painel de especialistas deve ser formado por três a seis membros. Também orientam que sejam realizados tantos painéis quantos forem necessários para a elucidação das questões e apontam o estabelecimento de critérios na escolha do perfil dos especialistas.

Em Sobral participaram seis pessoas, sendo dois residentes, dois preceptores de categoria, um tutor e o Coordenador do programa. Como critério de escolha, para o corpo docente houve a exigência que ele fosse egresso do programa de residência. Quanto à coordenação e residentes, o critério foi a disponibilidade em participar da validação.

Em Fortaleza, em contato prévio com a coordenação, foi sugerida a quantidade por segmento: três residentes, três tutores e três preceptores de categoria. Na ocasião compareceram três residentes, três preceptores de categoria, um tutor e a coordenação, totalizando oito participantes.

\section{Procedimentos para a coleta das informações}

Para a elaboração da matriz de autoavaliação optou-se pela fundamentação no referencial de Lima (2008), que propõe um modelo estrutural sistêmico de avaliação educacional em que o processo de identificação das estruturas essenciais de avaliação exige um conhecimento aprofundado acerca da gênese do objeto de estudo. Para isso, realizou-se uma imersão no arcabouço jurídico e normativo da educação na saúde, das residências multiprofissionais em saúde e na elaboração do estado da questão (Nóbrega e Therrien, 2004). Em um segundo momento, foi realizada a análise dos projetos pedagógicos mediante um roteiro preestabelecido que buscou identificar concepções de 
saúde, formação em serviço, avaliação educacional; levantar características do corpo docente, perfil de egresso, estratégias de ensino-aprendizagem, dinâmica de organização e funcionamento e gestão do programa; relacionar as concepções encontradas com o que a legislação preconizava, procurando agrupar as semelhanças e preservar as especificidades de cada programa como forma de permitir que as estruturas mapeadas pudessem ser empregadas em programas com diferentes realidades.

A partir do levantamento, leitura e análise dos projetos pedagógicos, voltou-se à matriz elaborada por Lima (2008), priorizando a estrutura de primeiro nível 'Curso', e as estruturas de segundo nível que mais bem representavam a realidade das RMSF.

\section{Procedimentos e instrumentos para a validação da matriz de autoavaliação}

O momento de validação das estruturas de avaliação adaptadas foi denominado de oficina de validação e foi utilizada a técnica painel de especialista. Struchiner, Ricciardi e Vetromille (1998) e Kristina, Majoor e Van Der Vleuten (2004) definem a técnica como um método em que profissionais experientes em diferentes aspectos relevantes do assunto avaliam a coerência, a pertinência e a validade da proposta apresentada. No caso da RMSF, a escolha do corpo docente, residentes e coordenação deu-se por acreditar que são eles que apresentam melhores condições de avaliar a pertinência e a coerência da matriz apresentada, contribuindo para o aprimoramento das estruturas identificadas, pois estariam no papel de stakeholders, como preconizado por Lima (2008).

Para a realização do painel de especialistas para validação da matriz de autoavaliação da residência adaptada do modelo estrutural-sistêmico, elaborou-se um roteiro consistindo de: apresentação do objeto, dos objetivos da pesquisa e explicações sobre o método adotado; apresentação do termo de consentimento livre e esclarecido; formação dos grupos por segmentos, entrega da matriz adaptada e dos instrumentos para validação; e plenária final. Utilizou-se uma pergunta geradora para motivar os especialistas a exporem suas impressões, críticas e sugestões sobre a matriz de autoavaliação. O procedimento foi gravado para subsidiar as análises das estruturas validadas.

O painel de especialistas para a matriz de autoavaliação foi realizado em cada local, com seus respectivos stakeholders. A duração do painel de especialistas variou entre duas horas (Fortaleza) e duas horas e meia (Sobral). A apreciação em grupo foi pensada pela possibilidade de propiciar discussões, o que foi confirmado nas duas validações. A validação Sobral contou com um tutor, dois preceptores, dois residentes e a Coordenação. Em Fortaleza, fizeram-se presentes dois tutores, três residentes, dois preceptores e a Coordenação. 


\section{Procedimentos para análise e interpretação das informações}

Para proceder à avaliação das falas dos especialistas utilizou-se a técnica de análise de conteúdo na modalidade temática, que consiste em descobrir os núcleos de sentido que compõem uma comunicação, cuja presença ou frequência signifiquem alguma coisa para o objeto analítico visado (Minayo, 2008).

Neste estudo, foram mapeados os discursos dos participantes, segundo os temas emergentes. Esse agrupamento permitiu a apreensão dos significados, a associação de ideias e a captação dos pensamentos expressos pelos participantes dos painéis de especialistas, o que possibilitou a identificação de quatro categorias de análise: apreciação da matriz que provocou reflexão e/ou julgamento sobre o próprio programa; contribuições da matriz de avaliação para o aperfeiçoamento dos programas; adequação da matriz validada a outros programas; as limitações da matriz validada.

O projeto deste estudo foi encaminhado à Comissão Científica da Secretaria de Saúde de Sobral, e em seguida submetido à apreciação do Comitê de Ética em Pesquisa da Universidade Estadual Vale do Acaraú, obtendo parecer favorável, n. 770/2010.

\section{Resultados e discussão}

Apresentamos os resultados decorrentes da validação da matriz de autoavaliação por meio da técnica de painel de especialistas. Num primeiro momento, mostra-se, em forma de quadro, um consolidado das sugestões realizadas na matriz das estruturas essenciais, que vão desde alterações na forma, no conteúdo e até mesmo de concepções, em que são descritas as contribuições dos especialistas e as condutas adotadas. Em outro quadro, apresenta-se uma avaliação do instrumento como um todo e sua pertinência, coerência e aplicabilidade a outros programas.

No item subsequente, analisamos, a partir do relato dos especialistas, suas impressões e percepções acerca das estruturas validadas, e, por fim, apresenta-se a versão da matriz das estruturas validadas com as alterações acatadas a partir do painel dos especialistas. 


\section{A validação da matriz autoavaliação}

O Quadro 1 apresenta a matriz adaptada para programas de residência multiprofissional em saúde da família. Apresentaremos apenas a estrutura do projeto pedagógico do referencial utilizado (Quadro 1) e a mesma estrutura já validada por especialistas (Quadro 2).

Quadro 1

Estrutura de projeto político-pedagógico adaptada do modelo estrutural-sistêmico de Lima (2008)

\begin{tabular}{|c|c|c|c|c|}
\hline \multicolumn{3}{|c|}{ Níveis de estruturas essenciais de avaliação } & \multicolumn{2}{|c|}{ Indicadores qualitativos, quantitativos e múltiplos } \\
\hline 1 Nível & 20 Nível & 3 Nível & Nome & Descrição \\
\hline \multirow[t]{2}{*}{ Curso } & \multirow{2}{*}{$\begin{array}{l}\text { Projeto } \\
\text { pedagógico } \\
\text { do programa }\end{array}$} & $\begin{array}{l}\text { 1.1 Concepção educacional } \\
\text { do programa }\end{array}$ & $\begin{array}{l}\text { 1.1.1 Concepção de } \\
\text { educação } \\
\text { 1.1.2 Concepção de } \\
\text { saúde } \\
\text { 1.1.3 Concepção de } \\
\text { ensino em serviço } \\
\text { 1.1.4 Concepção de } \\
\text { avaliação educacional } \\
\text { 1.1.5 Concepção de } \\
\text { formação em RMSF }\end{array}$ & $\begin{array}{l}\text { Descreve as concepçães de educação predominantes no Programa } \\
\text { de RMSF integradas aos princípios, crenças e valores da IES ou } \\
\text { serviço ao qual está vinculado. } \\
\text { Descreve a concepção de saúde condizente com os princípios do } \\
\text { SUS. } \\
\text { Descreve a concepção de ensino em serviço preconizada pela } \\
\text { CNRMS e legislação pertinente. } \\
\text { Descreve as concepções de avaliação voltadas para residências } \\
\text { multiprofissionais em saúde. } \\
\text { Descreve a concepção de formação em RMSF abordando seus } \\
\text { caracteres técnico, humano, social, político e ético. }\end{array}$ \\
\hline & & 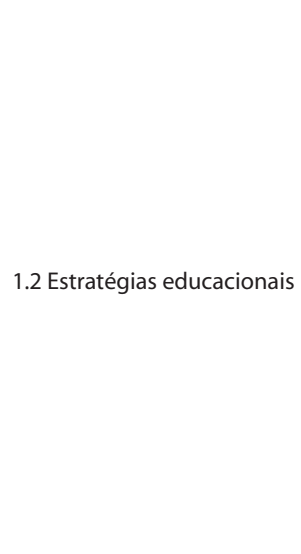 & $\begin{array}{l}\text { 1.2.1 Metodologias } \\
\text { educacionais } \\
\text { 1.2.2 Recursos } \\
\text { pedagógicos } \\
\text { 1.2.3 Integração } \\
\text { curricular } \\
\text { 1.2.4 Atingimento dos } \\
\text { objetivos }\end{array}$ & $\begin{array}{l}\text { Identifica e avalia a utilização e resultados das diversas estratégias } \\
\text { metodológicas educacionais adotadas pelo corpo docente no } \\
\text { programa de RMSF. } \\
\text { Identifica e avalia a qualidade e aplicabilidade dos diversos recursos } \\
\text { pedagógicos utilizados pelo corpo docente e residentes no } \\
\text { programa de RMSF. } \\
\text { Avalia a integração curricular do programa com os princípios do } \\
\text { SUS, da ESF e com as diretrizes propostas pela CNRMS. } \\
\text { Avalia o alcance dos objetivos propostos pelo programa de RMSF. }\end{array}$ \\
\hline
\end{tabular}


Continuação - Quadro 1

Estrutura do projeto político-pedagógico adaptada do modelo estrutural-sistêmico de Lima (2008)

\begin{tabular}{|c|c|c|c|c|}
\hline \multicolumn{3}{|c|}{ Níveis de estruturas essenciais de avaliação } & \multicolumn{2}{|c|}{ Indicadores qualitativos, quantitativos e múltiplos } \\
\hline 1॰ Nível & 2 Nível & 3 Nível & Nome & Descrição \\
\hline \multirow{4}{*}{ Curso } & \multirow{4}{*}{$\begin{array}{l}\text { Projeto } \\
\text { pedagógico } \\
\text { do programa }\end{array}$} & 1.3 Corpo docente & $\begin{array}{l}\text { 1.3.1 Tutoria } \\
\text { 1.3.2 Preceptoria } \\
\text { 1.3.3 Educação } \\
\text { permanente para o } \\
\text { corpo docente } \\
\text { 1.3.4 Qualificação do } \\
\text { corpo docente }\end{array}$ & $\begin{array}{l}\text { Explicita o conceito de tutoria e sua função na formação em RMSF. } \\
\text { Explicita o conceito de preceptoria e sua função na formação em RMSF. } \\
\text { Explicita e realiza ações de educação permanente para o corpo } \\
\text { docente da RMSF. } \\
\text { Explicita e oportuniza incentivos à formação do corpo docente, } \\
\text { como acesso a mestrado, doutorado e ou participação em eventos } \\
\text { em área de interesse da RMSF. }\end{array}$ \\
\hline & & 1.4 Corpo discente & $\begin{array}{l}\text { 1.4.1 Residente } \\
\text { 1.4.2 Perfil do egresso }\end{array}$ & $\begin{array}{l}\text { Explicita o conceito de residente e suas atribuições na RMSF. } \\
\text { Define o perfil do egresso do programa de RMSF. }\end{array}$ \\
\hline & & $\begin{array}{l}1.5 \text { Cenários de } \\
\text { aprendizagem }\end{array}$ & $\begin{array}{l}\text { 1.5.1 Atividades em } \\
\text { serviço na ESF } \\
\text { 1.5.2 Atividades no } \\
\text { território } \\
\text { 1.5.3 Atividades nas } \\
\text { redes de atenção em } \\
\text { saúde } \\
\text { 1.5.4 Atividades } \\
\text { teórico-conceituais }\end{array}$ & $\begin{array}{l}\text { Explicitam a carga horária e a forma como se dará a formação do } \\
\text { residente na ESF e sua articulação com as equipes de SF. } \\
\text { Explicitam a carga horária e as atividades destinadas ao território } \\
\text { como espaço de aprendizagem. } \\
\text { Explicitam a carga horária destinada ao residente nas Redes de } \\
\text { Atenção em Saúde como cenário de aprendizagem. } \\
\text { Explicitam a carga horária destinada aos momentos teórico-conceituais. }\end{array}$ \\
\hline & & $\begin{array}{l}\text { 1.6 Estratégias de } \\
\text { aprendizagem } \\
\text { multiprofissional e } \\
\text { interdisciplinar (campo) }\end{array}$ & $\begin{array}{l}\text { 1.6.1 Atividades } \\
\text { teórico-conceituais } \\
\text { 1.6.2 Atividades práticas } \\
\text { 1.6.3 Atividades } \\
\text { teórico-práticas }\end{array}$ & $\begin{array}{l}\text { Descrevem como estão organizadas as estratégias metodológicas } \\
\text { para a realização das atividades teórico-conceituais na RMSF, } \\
\text { articulando o campo comum da ESF para todas as profissões. } \\
\text { Descrevem as estratégias metodológicas de desenvolvimento das } \\
\text { atividades práticas na RMSF, articulando o campo comum da ESF } \\
\text { para todas as profissões. } \\
\text { Descrevem as estratégias metodológicas de desenvolvimento das } \\
\text { atividades teórico-práticas, articulando o campo comum para todas } \\
\text { as profissões. }\end{array}$ \\
\hline
\end{tabular}


Continuação - Quadro 1

Estrutura do projeto político-pedagógico adaptada do modelo estrutural-sistêmico de Lima (2008)

\begin{tabular}{|c|c|c|c|c|}
\hline \multicolumn{3}{|c|}{ Níveis de estruturas essenciais de avaliação } & \multicolumn{2}{|c|}{ Indicadores qualitativos, quantitativos e múltiplos } \\
\hline 1Nível & 2॰ Nível & 3० Nível & Nome & Descrição \\
\hline \multirow{3}{*}{ Curso } & \multirow{3}{*}{$\begin{array}{l}\text { Projeto } \\
\text { pedagógico } \\
\text { do programa }\end{array}$} & $\begin{array}{l}1.7 \text { Estratégias de } \\
\text { aprendizagem para os } \\
\text { núcleos de saberes }\end{array}$ & $\begin{array}{l}\text { 1.7.1 Atividades } \\
\text { teórico-conceituais } \\
\text { 1.7.2 Atividades } \\
\text { práticas } \\
\text { 1.7.3 Atividades } \\
\text { teórico-práticas }\end{array}$ & $\begin{array}{l}\text { Descrevem como estão organizadas as estratégias metodológicas } \\
\text { para a realização das atividades teórico-conceituais na RMSF, } \\
\text { correspondentes ao núcleo de saberes de cada profissão com vistas } \\
\text { a preservar sua identidade profissional. } \\
\text { Descrevem as estratégias metodológicas de desenvolvimento das } \\
\text { atividades práticas na RMSF, correspondentes ao núcleo de saberes } \\
\text { de cada profissão com vistas a preservar sua identidade profissional. } \\
\text { Descrevem as estratégias metodológicas de desenvolvimento das } \\
\text { atividades teórico-práticas, correspondentes ao núcleo de saberes } \\
\text { de cada profissão com vistas a preservar sua identidade profissional. }\end{array}$ \\
\hline & & 1.8 Integração ensino-serviço & $\begin{array}{l}\text { 1.8.1 Ações de } \\
\text { integração ensino- } \\
\text {-serviço-comunidade } \\
\text { 1.8.2 Processo } \\
\text { educativo com foco } \\
\text { nas necessidades da } \\
\text { população/território } \\
\text { 1.8.3 Articulação com } \\
\text { os movimentos sociais } \\
\text { e ou controle social do } \\
\text { território } \\
\text { 1.8.4 Articulação com } \\
\text { outras modalidades } \\
\text { de formação no } \\
\text { âmbito da ESF }\end{array}$ & $\begin{array}{l}\text { Avalia a articulação do Programa de Residência Multiprofissional em } \\
\text { Saúde da Família com movimentos sociais e/ou controle social do } \\
\text { território. } \\
\text { Avalia a integração do programa de RMSF com outras modalidades } \\
\text { de formação que ocorrem nos serviços da ESF, como ensino técnico, } \\
\text { graduação, PET-Saúde e Residência de Medicina de Família e } \\
\text { Comunidade. }\end{array}$ \\
\hline & & 1.9 Sistema de avaliação & $\begin{array}{l}\text { 1.9.1 Avaliação da } \\
\text { aprendizagem } \\
\text { discente } \\
\text { 1.9.2 Avaliação docente } \\
\text { 1.9.3 Avaliação do } \\
\text { cenário de } \\
\text { prática/serviços }\end{array}$ & $\begin{array}{l}\text { Explicita o sistema de avaliação para o residente, informando as } \\
\text { estratégias de avaliação dos diversos componentes da formação na } \\
\text { modalidade RMSF, teórico-conceitual, prático e teórico-prático, por } \\
\text { parte do corpo docente e profissionais da ESF. } \\
\text { Explicita estratégias de avaliação do corpo docente da RMSF por } \\
\text { parte dos residentes. } \\
\text { Explicita estratégias de avaliação dos residentes no cenário de } \\
\text { prática/serviços por parte dos profissionais que compõem as } \\
\text { equipes da ESF. }\end{array}$ \\
\hline
\end{tabular}

Fonte: Os autores.

Nota: RMSF: Residência Multiprofissional em Saúde da Família; IES: Instituição de Ensino Superior; CNRMS: Comissão Nacional de Residências Multiprofissionais em Saúde; ESF: Estratégia Saúde da Família; SF: Saúde da Família; PET: Programa de Educação pelo Trabalho. 
Quadro 2

Estrutura de projeto político-pedagógico - Validada por especialistas

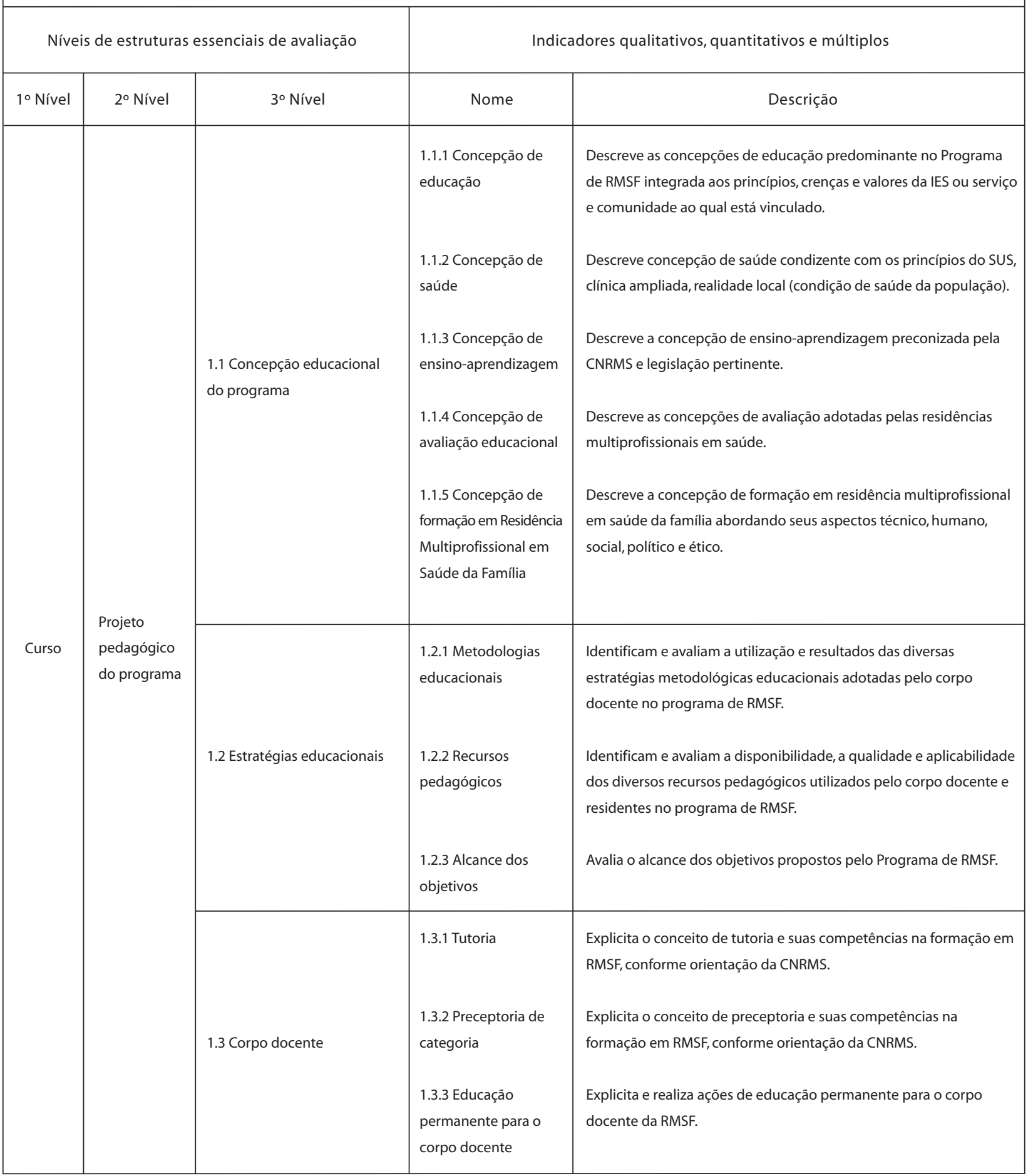


Continuação - Quadro 2

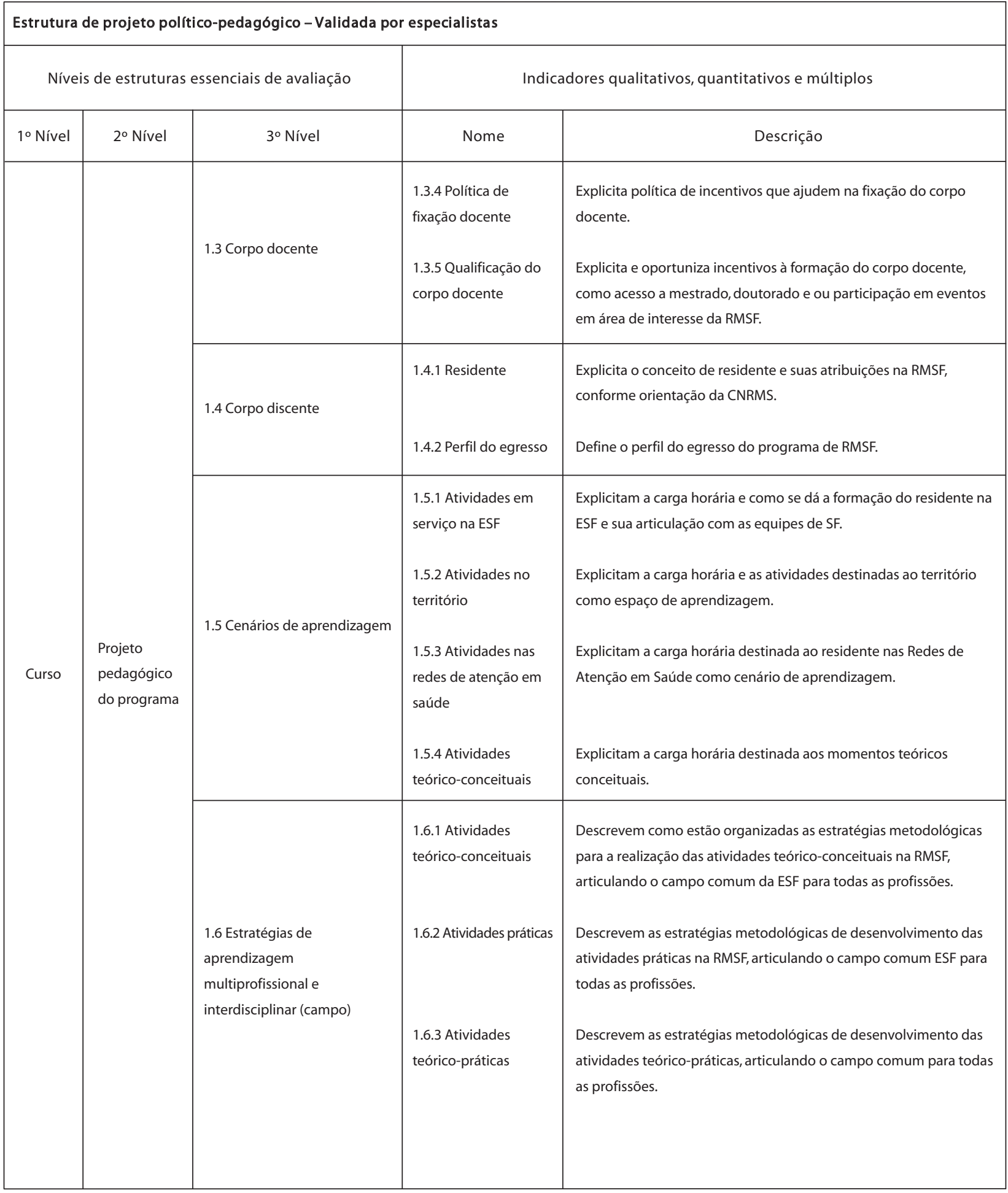


Continuação - Quadro 2

Estrutura do projeto político-pedagógico - Validada por especialistas

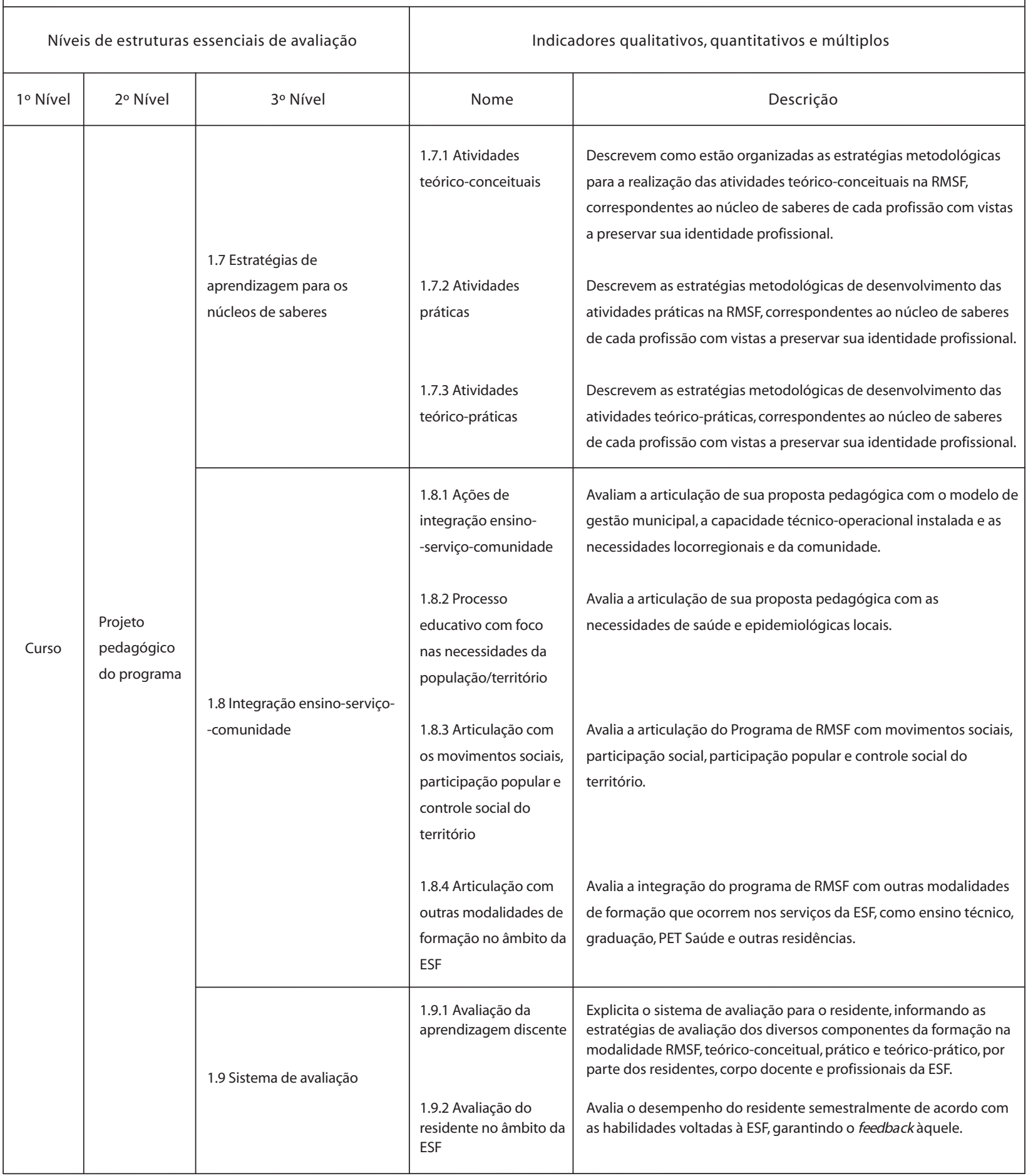


Continuação - Quadro 2

\begin{tabular}{|c|c|c|c|c|}
\hline Níve & de estruturas & ssenciais de avaliação & Indica & lores qualitativos, quantitativos e múltiplos \\
\hline 1Nível & 2o Nível & 3Nível & Nome & Descrição \\
\hline Curso & $\begin{array}{l}\text { Projeto } \\
\text { pedagógico } \\
\text { do programa }\end{array}$ & 1.9 Sistema de avaliação & $\begin{array}{l}\text { 1.9.3 Avaliação da } \\
\text { competência técnica- } \\
\text {-humanizada dos } \\
\text { residentes } \\
\text { 1.9.4 Avaliação docente } \\
\text { 1.9.5 Avaliação do } \\
\text { cenário de } \\
\text { prática/serviços } \\
\text { 1.9.6 Autoavaliação do } \\
\text { programa de RMSF }\end{array}$ & $\begin{array}{l}\text { Explicita como avalia a capacidade do residente em lidar com a } \\
\text { realidade do território, com sensibilidade, visão crítica e } \\
\text { resolutividade. } \\
\text { Explicita estratégias de avaliação do corpo docente da RMSF por } \\
\text { parte dos residentes, docentes e coordenação. } \\
\text { Explicita estratégias de avaliação dos residentes no cenário de } \\
\text { prática/serviços por parte dos profissionais que compõem as } \\
\text { equipes da ESF e usuários. } \\
\text { Explicita proposta de autoavaliação do Programa de RMSF por parte } \\
\text { dos residentes, tutores, preceptores, gestores, usuários e profissionais } \\
\text { dos serviços. }\end{array}$ \\
\hline
\end{tabular}

Fonte: Os autores.

Nota: RMSF: Residência Multiprofissional em Saúde da Família; IES: Instituição de Ensino Superior; CNRMS: Comissão Nacional de Residências Multiprofissionais em Saúde; ESF: Estratégia Saúde da Família; SF: Saúde da Família; PET: Programa de Educação pelo Trabalho.

A estrutura projeto político-pedagógico foi a que recebeu maior atenção e considerações por parte dos especialistas, totalizando 28 sugestões, entre alterações, acréscimos e exclusão de itens.

A definição do citado projeto advém da compreensão, quanto ao sentido de político, das "opções, escolhas de caminhos e prioridades na formação do cidadão como membro ativo e transformador da sociedade em que vive", e de pedagógico, porque "expressa as atividades pedagógicas e didáticas que levam a escola a alcançar os seus objetivos educacionais" (Betini, 2005, p. 39). As dimensões política e pedagógica possuem um significado indissociável, definido como um processo permanente de reflexão em busca da efetivação das intenções do projeto.

Os dois projetos pedagógicos utilizados como unidades de análise para identificação das estruturas essenciais de avaliação apresentam, de forma clara, suas intencionalidades e seu compromisso ético-político com o ideário da reforma sanitária brasileira e com os princípios do SUS e das Residência Multiprofissionais em Saúde (RMS). 
Na estrutura educacional do programa, foram sugeridas alterações que permitem maior clareza acerca das concepções e estão em consonância com os princípios e diretrizes das residências multiprofissio-nais em saúde.

Destaca-se como contribuição relevante a substituição do indicador 'concepção de ensino em serviço' pela 'concepção de ensino-aprendizagem', pois, apesar de a modalidade residência ser definida, inclusive legalmente, como ensino em serviço, para um processo de avaliação de um programa educacional a concepção de ensino-aprendizagem se mostra mais coerente e abrangente.

No entanto, sendo a RMS modalidade de formação em serviço, é preciso que essa compreensão esteja clara no momento de formulação da avaliação; assim reitera-se a afirmação de Ceccim e Feuerweker (2004a; 2004b) de que só por meio da educação em serviço é possível pensar um sistema de saúde baseado na integralidade, pois permite articular gestão, atenção, ensino e controle social no enfrentamento de problemas reais de cada equipe, ou seja, pensar o processo de ensino-aprendizagem com foco na educação em serviço.

Todas as outras sugestões de alterações, nessa estrutura, foram acatadas, por serem consideradas pertinentes, pois se trata de questões do campo conceitual que devem perpassar a proposta pedagógica dos programas, mas, principalmente, devem estar fundamentadas em uma concepção ampliada de saúde e em constante diálogo com os princípios e diretrizes do SUS; afinal, segundo Oliveira (2009, p.76), “a Residência Multiprofissional em Saúde apresenta-se não apenas como uma iniciativa de formação técnica, mas como um importante movimento político e de ordenação social para a garantia da consolidação do SUS".

A estrutura 'estratégias educacionais' recebeu algumas sugestões de alterações na descrição dos indicadores, assim como a retirada do indicador 'integração curricular', que já está contido na estrutura currículo, e o acréscimo do indicador de avaliação de desempenho do residente, o qual já está contemplado na estrutura 'sistema de avaliação'.

A estrutura 'corpo docente' recebeu sugestões de alterações quase exclusivamente na descrição dos indicadores referentes à substituição da expressão 'função' por 'competências' para a tutoria e preceptoria. Também foi sugerido acrescentar à tutoria a expressão preceptoria de território, como é designado no programa de Fortaleza, o que não foi considerado pertinente, pois tutoria é uma definição que está contida na legislação das residências e nacionalmente normatizada entre os programas e pela Comissão Nacional de Residências Multiprofissionais em Saúde (CNRMS). Outra sugestão foi a criação de mais um indicador que avaliaria a política de incentivo à permanência do corpo docente no programa, pois alegou-se que há dificuldades em fixar os docentes devido à situação de precarização das relações de trabalho.

Segundo a resolução das diretrizes pedagógicas para programas de RMS (Brasil, 2012), a definição da tutoria se dá no nível de campo: 
Corresponde à atividade de orientação acadêmica voltada à discussão das atividades teóricas, teórico-práticas e práticas desenvolvidas pelos preceptores e residentes, no âmbito de conhecimento, integrando os núcleos de saberes e práticas das diferentes profissões que compõem a área de concentração do programa (Brasil, 2012).

A função do tutor de núcleo corresponde “à atividade de orientação acadêmica voltada à discussão das atividades teóricas, teórico-práticas e práticas do núcleo específico profissional, desenvolvidas pelos preceptores e residentes" (Brasil, 2012). Entretanto, nos projetos pedagógicos analisados, permanece a função docente de tutoria compreendida como o docente responsável pela articulação do processo ensino-aprendizagem na perspectiva do campo do cuidado, defendida por Campos (2000) como espaço de diálogo entre os diferentes saberes e práticas das diversas categorias que compõem as equipes multiprofissionais das residências.

Não foi identificada nos projetos político-pedagógicos a função de tutoria de núcleo, como preconizado pela minuta da CNRMS (Brasil, 2012). O que prevalece é o preceptor como aquele que se preocupa com o núcleo, a especificidade de cada categoria, mas sempre tentando articulá-lo com a interdisciplinaridade e a multiprofissionalidade, e não meramente como definido pelo mesmo documento, em que "se caracteriza por supervisão direta das atividades práticas desenvolvidas pelos residentes nos serviços de saúde" (Brasil, 2012), o que demonstra uma visão reducionista da função de preceptoria, pois a experiência tem evidência de que a função do preceptor também envolve aspectos teóricos e teórico-práticos.

Segundo Parente (2008),

tutores e preceptores mediam relações, facilitam a inserção nos territórios e criam um ambiente metodológico que potencializa a aprendizagem e o trabalho interdisciplinar. Assim, as ações que melhor expressariam as funções de tutores e preceptores, seriam 'aqueles que ajudam a construir caminhos, apoiam, mediam' (Parente, 2008, p. 51).

Em relação à estrutura corpo discente sugeriu-se que se acrescentasse, ao final da redação do indicador que trata da definição e atribuições dos residentes, a expressão 'conforme orientações da CNRMS', o que revela a preocupação de que os programas procurem pautar-se nas regulamentações do órgão regulador dessa formação.

Na estrutura 'cenários de aprendizagem', os especialistas identificaram aspectos importantes que não haviam sido contemplados pelos indicadores construídos e sugeriram a criação de dois novos indicadores. O primeiro deverá permitir a avaliação da infraestrutura dos serviços que se constituam 
como cenários de aprendizagem. O outro foi a criação de um novo indicador que avalie a estrutura e dinâmica das equipes de Saúde da Família no processo de ensino-aprendizagem dos residentes.

Esses dois aspectos foram considerados como questões que afetam o processo de ensino-aprendizagem dos residentes e que têm sido negligenciados nos processos de avaliação dos programas. Segundo Schaedler (2010), na oficina sobre avaliação promovida pela CNRMS no $3^{\circ}$ Seminário Nacional de Residências Multiprofissionais em Saúde, ocorrido em Brasília no ano de 2008, os participantes propuseram a criação de eixos estruturantes de avaliação que permitissem entender aspectos como oferta de vagas, infraestrutura, questões pedagógicas, de realidade social, questões políticas, avanços e dificuldades encontradas e produzidas pela e na residência.

De uma forma geral, o processo de avaliação das residências tem assumido um caráter heterogêneo que irá variar de programa para programa, conforme explicita Santos (2010) ao dizer que “os próprios entrevistados identificam uma lacuna, quando percebem que os profissionais mais diretamente ligados aos residentes, no cotidiano do trabalho, não são avaliados" (Santos, 2010, p. 79).

\section{Quadro 3}

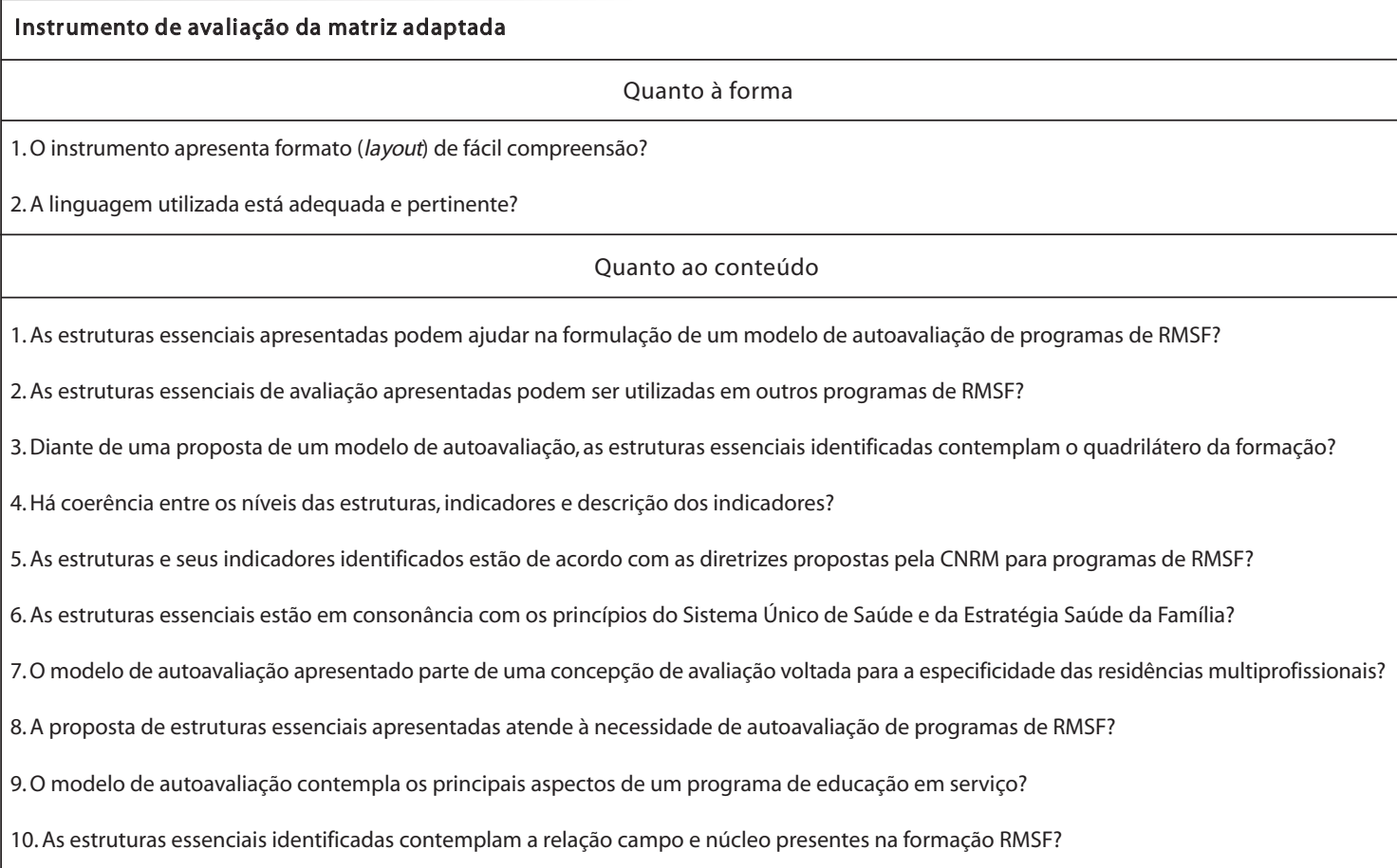


O Quadro 3 foi utilizado para que os especialistas pudessem avaliar o instrumento apresentado considerando os aspectos forma e conteúdo.

Nos itens referentes à forma, o instrumento foi considerado como adequado e obteve $100 \%$ de concordância, tanto na adequação do formato, ou layout, como na linguagem; mas os residentes de Fortaleza fizeram a ressalva de que não estaria adequada ao público como usuários e profissionais dos Centros de Saúde da Família que não tinham proximidade com a residência.

A análise do conteúdo foi pensada para que os especialistas avaliassem a coerência e a pertinência das estruturas identificadas e adaptadas à concepção de formação em serviço e com todo o arcabouço jurídico-legal e teórico das residências multiprofissionais em saúde, além da adequação à referida modalidade de formação e, principalmente, à possibilidade de extensão a outras realidades.

Nos itens de 1 a 6, procurou-se investigar na adequação das estruturas essenciais de avaliação de programas de RMSF, apresentadas no instrumento à formulação de um modelo de autoavaliação, a possibilidade de utilização delas em outros programas em âmbito nacional, e a consonância com o quadrilátero da formação em saúde, bem como a existência de coerência entre as estruturas, os indicadores e suas descrições. Os especialistas assinalaram sim em todos eles, com $100 \%$ de concordância.

Outro aspecto imprescindível de ser avaliado em relação às estruturas propostas é se elas estavam voltadas para a realidade e especificidade das residências, pois o modelo estrutural-sistêmico proposto por Lima (2008) teve como objeto o curso presencial de graduação de Administração Geral ou de Empresas em faculdades isoladas e privadas. No item 7, fazia-se necessário avaliar se o processo de adaptação havia conseguido dar conta da especificidade do objeto "Residência Multiprofissional em Saúde da Família no Ceará" e todas as suas diferenças com o objeto que deu origem ao modelo estrutural-sistêmico.

De maneira geral, os especialistas consideraram as estruturas apresentadas para a validação como coerentes com o que se espera de uma formação em residência multiprofissional, como apontam Ferla e Ceccim (2003, apud Lobato, 2010, p. 34); uma formação idealizada para desencadear processos que tragam humanização, acolhimento, responsabilização para com o usuário, ação multiprofissional e integral, resolutividade nos serviços de saúde e produção de autonomia no cuidado.

A preocupação se as estruturas adaptadas atenderiam à necessidade de autoavaliação dos programas foi o objetivo do item 8, onde todos responderam que sim. O que leva a supor que as cinco matrizes apresentadas contemplam os aspectos relevantes a serem considerados em um modelo de autoavaliação das RMSF. 
Os itens 9 e 10 se complementam, pois ambos investigam a organicidade entre as estruturas apresentadas e validadas e os princípios norteadores da formação em serviço, bem como a 'novidade' da formação multiprofissional, a relação campo e núcleo. Em ambos, os avaliadores consideraram que o instrumento apresentava coerência com a formação em residência multiprofissional e deu conta da relação campo e núcleo.

Ao final da validação dos painéis das estruturas, realizou-se um momento de partilha em que os especialistas podiam dizer de suas impressões sobre a matriz e outras questões que considerassem pertinentes; para isso, a pesquisadora convidava-os a expressar suas opiniões em uma frase geradora. Esse momento teve como objetivo levantar opiniões sobre o instrumento, captando impressões, percepções que complementariam o momento de validação, trazendo à tona questões que somente a validação não traria.

Foi um exercício gostoso, porque a gente foi fazendo a avaliação do programa, os meninos foram dizendo: a gente tá avaliando a residência, e a gente realmente ficou 'avaliando o programa' (Residente 3).

De certa forma, quando a gente ia fazendo a avaliação, a gente ia avaliando o programa, aí dizia: peraí (sic), gente, não é hora de ir avaliando o programa, é hora de ir avaliando o instrumento (Residente 5).

$\mathrm{Na}$ hora que eu estava fazendo o instrumento, era como se eu estivesse trilhando a caminhada da residência multi até chegar à avaliação (Docente E).

A autoavaliação institucional deve ter um caráter pedagógico e de autorregulação, "deve buscar compreender a cultura e a vida de cada instituição em suas múltiplas manifestações" (Instituto Nacional de Estudos..., 2007, p. 109). É um processo essencialmente social e coletivo que busca produzir conhecimentos sobre a instituição para transformá-la.

No modelo estrutural-sistêmico, a autoavaliação de um curso significa amplo

processo de autorreflexão sobre as suas estruturas essenciais e sistemas componentes, a partir da atuação avaliativa dos seus stakeholders (...) sob a normatividade de princípios de autoavaliação construídos e ou aperfeiçoados por essa comunidade institucional (...) e por um contrato de autoavaliação estruturado em indicadores de desenvolvimento educacional e institucional, de cunho quantitativo e/ou qualitativo (Lima, 2008, p.356).

O contato com a matriz das estruturas essenciais de avaliação possibilitou um exercício de avaliação do programa de forma quase imediata, o que 
de certa forma revela a adequação da proposta aos programas avaliados e a pertinência da matriz validada.

Outra fala recorrente foi a possibilidade vislumbrada pelos avaliadores sobre a contribuição trazida pela possível criação de um instrumento de avaliação a partir das estruturas validadas dos programas, ajudando-os a se aperfeiçoar:

Eu acho que acaba criando um roteiro para o docente e pro discente, de como trilhar essa caminhada durante esses dois anos... se a gente conseguisse enxugar isso mais ainda, para tornar isso uma sala de situação da própria residência, ia contribuir muito no processo de avaliação... porque nossa maior dificuldade é nos indicadores de avaliação, que dão a qualidade do programa (Docente G).

Ela (a matriz) dá conta de nos provocar, né, a gente ver (sic) o como a gente tá trabalhando e a magnitude (que o) nosso trabalho tem alcançado, não nos cria uma ansiedade, mas abre um horizonte do como a gente tem que direcionar o nosso trabalho (Docente $\mathrm{H}$ ).

A avaliação pode ser um potente dispositivo de problematização e de mudança do ensino e de acompanhamento da qualidade pedagógica de instituições e serviços. Assim, diz Schaedler (2010),

o produto mais importante do processo avaliativo é gerar mobilização pelo aperfeiçoamento educativo e organizar processos coletivos de qualificação (...) num processo permanente de melhoramento da qualidade e de fortalecimento de seu compromisso social (Schaedler, 2010, p. 146).

Ainda segundo Lima (2008, p. 393), o “intuito da autoavaliação é uma autorreferência, uma autocrítica que visa a um desenvolvimento, embora influenciada por variáveis externas de contexto". Dessa forma, a implantação de uma proposta de autoavaliação para os programas de RMSF pode ajudá-los no aprimoramento de suas propostas pedagógicas e metodológicas.

Quanto à possibilidade de as estruturas validadas serem aplicáveis a outras realidades,

De uma forma geral, ele tá muito bom, consegue contemplar aspectos não só referentes à nossa residência, mas outro programa que quiser utilizar, dá para se adequar tranquilamente (Docente A).

A aplicabilidade às outras realidades foi considerada possível, apesar de os programas possuírem particularidades regionais e de concepções. Mas a 
existência de diretrizes mínimas por parte dos órgãos reguladores e financiadores permite que os resultados desta pesquisa possam ser generalizados, com o cuidado do qual nos fala Lima (2008) sobre a atitude avaliativa-científica precisar estar contextualizada por variáveis políticas, éticas e sociais que impactam no seu progresso e no seu resultado. Esse contexto ambiental endógeno e exógeno constitui-se de variáveis teleológicas e não teleológicas que precisam ser consideradas na avaliação. Ou seja, uma avaliação estrutural-sistêmica precisa tomar em consideração o contexto no qual está inserido o objeto a ser avaliado, com suas variáveis endógenas e exógenas, teleológicas e não teleológicas.

A matriz foi considerada extensa e cansativa, como demonstram os depoimentos a seguir

Sobre a questão de ele ser extenso é até pertinente; pela complexidade do programa de residência, não é uma questão fácil de relacionar. É complexa e eu acho que a isso se deve a extensão da estrutura e do instrumento (Residente 3).

Por ele ser muito completo, ele acaba sendo extenso, pode se tornar cansativo, de que forma fazer para que ele seja completo sem se tornar cansativo; quando você está fazendo uma avaliação e se torna cansativo, ao final a gente não consegue dedicar a mesma atenção que dedicou no início (Docente A).

Outra questão levantada como limitação foi a linguagem adotada, que não estaria adequada para ser utilizada com usuários e alguns trabalhadores dos Centros de Saúde da Família (CSF).

Caso haja o interesse de avaliar a partir dos usuários, não seria cabível utilizar esse instrumento com eles, nem com usuários nem com alguns profissionais dos CSF que não estão familiarizados com alguns termos, como teórico-prático, teórico-conceitual, alguns conceitos que eu acho que deveriam ser demarcados (Residente 3).

Quanto à extensão da matriz validada, isso deveu-se à complexidade do objeto avaliado e à coerência com a matriz estrutural-sistêmica de Lima (2008). Como se tratava de avaliar junto aos especialistas a pertinência, viabilidade e coerência da matriz adaptada para programas de RMSF, optou-se por apresentar as estruturas que foram consideradas como importantes para compor uma futura proposta de autoavaliação, e que, apesar de considerada extensa no momento da validação, não foi solicitada a retirada de itens, e sim inclusão de outros.

No quesito adequação da linguagem, foi adotada a linguagem utilizada no arcabouço jurídico e teórico das residências multiprofissionais. Entretanto, 
no momento de estruturação de um instrumento de autoavaliação, essa sugestão precisa ser considerada.

\section{Considerações finais: encerrando o percurso, retomando o caminho}

A RMSF, objeto deste estudo, adentrou o cenário da formação em saúde postulando a contra-hegemonia ao modelo de formação biomédica, curativista e individual. Entretanto, à medida que os anos foram passando, várias incertezas surgiram. Parte delas foi sendo transformada em questionamentos acerca do seu caráter inovador e de sua eficácia na produção da integralidade da atenção e do cuidado à saúde.

A ausência de normatizações e regulamentações das residências multiprofissionais desencadeou uma diversidade de propostas pedagógicas que, de certa forma, dificultaram a busca de evidências quanto à sua efetividade e sua consonância com os princípios e diretrizes do SUS e da Estratégia Saúde da Família.

Além de indefinições no campo pedagógico e metodológico, há um vazio no campo da avaliação, seja por falta de parâmetros mínimos, seja pela incipiência de métodos e instrumentais. Quanto à avaliação para residências multiprofissionais em saúde, existe, segundo Schaedler (2010, p. 150), um consenso: ela deve ser "(...) dialógica, processual, participativa e formativa". Entretanto, afirma que, apesar de ser uma boa ideia, necessita de práticas e de movimentos.

O presente estudo procurou sistematizar uma proposta de estruturas essenciais de avaliação para RMSF a partir do referencial estrutural-sistêmico com o objetivo de subsidiar a elaboração de projetos de autoavaliação para esses programas.

Na busca de responder à questão da pesquisa que norteou este estudo, qual seja, "Como identificar as estruturas essenciais de avaliação em programas de RMSF para uma proposta de autoavaliação?", a pesquisa mostrou ser possível essa identificação, o que exigiu a necessária busca pela gênese do objeto no campo teórico e jurídico. Entretanto, essa identificação poderia ter sido mais orgânica se houvesse mais sistematizações sobre as residências multiprofissionais, inclusive sobre a avaliação dessas, seja do ponto de vista interno, seja do externo.

As estruturas validadas revelaram que os programas de RMSF no Ceará precisam refletir, em suas propostas pedagógicas, os princípios do SUS, com destaque para a integralidade. Necessitam considerar a diversidade de cenários de aprendizagem, além de terem em consideração a realidade institucional e a realidade locorregional, e de estabelecerem um diálogo permanente com o que foi denominado por Ceccim e Feuerwerker (2004b) de 
quadrilátero da formação: atenção, gestão, ensino e controle social. Isso é condição sine qua non para que a residência se constitua como alternativa ao modelo biomédico hegemônico.

Os resultados também apontam para a necessidade de propostas de avaliação que deem conta de avaliar o processo de ensino-aprendizagem na perspectiva do núcleo e do campo, além das atividades de ensino em serviço, não se restringindo somente a atividades teórico-conceituais comumente adotadas pelos programas.

Com base nos relatos dos especialistas, é possível identificar que o momento da validação provocou reflexões e despertou, junto a tutores, preceptores e residentes, a necessidade de se utilizar a autoavaliação como estratégia de aprimoramento institucional e do programa. A adequação das estruturas adaptadas e validadas às realidades de outros programas também foi apontada pelos especialistas como possível. Entretanto, limitações do instrumento foram identificadas, tais como a extensão, o que poderia torná-lo cansativo, e a linguagem utilizada, considerada restrita ao universo das residências multiprofissionais, o que dificultaria a aplicação aos trabalhadores e usuários da saúde.

A adaptação e validação das estruturas essenciais de avaliação de programas de RMSF no Ceará sinalizam para a relevância de uma proposta de autoavaliação das residências multiprofissionais que fuja das avaliações 'tradicionais' e que se torne um processo tão inventivo quanto se deseja das residências.

Nesse sentido, é necessário ir construindo uma concepção de avaliação que, além de se propor dialógica, processual, participativa e formativa, aponte caminhos de como isso pode se materializar no cotidiano dos programas. Assim, as estruturas aqui validadas são ofertadas como possíveis caminhos a serem trilhados pelas residências, com o devido cuidado de dialogar permanentemente com a realidade na qual estão inseridas (Lima, 2008), sem perder de vista o projeto ético-político de sociedade do qual fazem parte.

\section{Colaboradores}

A elaboração, a análise, a discussão e a revisão do artigo foram feitas por Maristela Inês Osawa Vasconcelos e Francisca Lopes de Souza. Geison Vasconcelos Lira e Maria Socorro de Araújo Dias colaboraram na discussão e na revisão final do artigo, e Geórgia Sibele Nogueira da Silva contribuiu na revisão final do manuscrito. 
Resumen La Residencia Multiprofesional en Salud de la Familia se caracteriza como formación en servicio que promueve la aproximación con la realidad del Sistema Único de Salud. A pesar de existir empíricamente la constatación de resultados positivos en la actuación profesional, no hay un modelo de evaluación de los resultados. Este artículo se detiene en la descripción y el análisis del proceso de adaptación y validación de estructuras esenciales de evaluación y sus respectivos indicadores, para la construcción de modelos de autoevaluación para programas de residencias multiprofesionales en salud de la familia. En un taller, se presentaron instrumentos a los especialistas, que deberían hacer consideraciones sobre éstos. Las observaciones se analizaron y las que se consideraron pertinentes a los objetivos de evaluación fueron acatadas. La construcción y la validación de indicadores de autoevaluación de programas de Residencia Multiprofesional en Salud de la Familia, aquí realizadas, señalan la relevancia de una propuesta que supere las evaluaciones "tradicionales" y se vuelva un proceso tan inventivo como se desea en las residencias.

Palabras clave evaluación de programas y proyectos de salud; internado y residencia; programa salud de la familia.

\section{Notas}

1 Universidade Estadual Vale do Acaraú, Centro de Ciências da Saúde, Sobral, Ceará, Brasil.

$<$ miosawa@gmail.com>

Correspondência: Rua Balbino, 328, Campo dos Velhos, CEP 62.040-200, Sobral, Ceará, Brasil.

2 Prefeitura Municipal de Sobral, Secretaria da Saúde, Escola de Formação em Saúde da Família Visconde de Saboia, Sobral, Ceará, Brasil.

$<$ franciscalsouza2006@yahoo.com.br>

3 Universidade Federal do Ceará, Programa de Pós-Graduação em Saúde da Família, Sobral, Ceará, Brasil.

<geisonlira@terra.com.br>

4 Universidade Estadual Vale do Acaraú, Centro de Ciências da Saúde, Sobral, Ceará, Brasil.

<socorroad@gmail.com>

5 Universidade Federal do Rio Grande do Norte, Centro de Ciências Humanas, Letras e Artes, Departamento de Psicologia, Natal, Rio Grande do Norte, Brasil.

<gsibele@uol.com.br>

6 A pesquisa "Construção e Validação de Indicadores de Efetividade da Formação nos Programas de Residência Multiprofissional em Saúde da Família", que deu origem a este artigo, foi fruto do trabalho idealizado e coordenado por Maristela Inês Osawa Chagas, edital n. 02/2009 da Fundação Cearense de Apoio ao Desenvolvimento Científico e Tecnológico (FUNCAP) em parceria com o Ministério da Saúde (MS), Conselho Nacional de Desenvolvimento Científico e Tecnológico (CNPq) e Secretaria da Saúde do Estado do Ceará (SESA), no âmbito do Programa Pesquisa para o SUS: gestão compartilhada em saúde (PPSUS). 


\section{Referências}

BETINI, Geraldo A. A construção do projeto político-pedagógico na escola. EDUC@ção. Rev. Ped. UniPinhal, São Paulo, v. 1, n. 3, jan./dez., 2005.

BRASIL. Ministério da Educação. Comissão Nacional de Residência Multiprofissional e em Área Profissional da Saúde. Resolução n. 2 de 13 de abril de 2012. Dispõe sobre diretrizes pedagógicas dos programas de residência multiprofissional e em área profissional da saúde. Diário Oficial da União. Brasília, 16 de abr. 2012. Seção I, p. 24-25.

CAMPOS, Gastão W. S. Saúde pública e saúde coletiva: campo e núcleo de saberes e práticas. Ciência \& Saúde Coletiva, Rio de Janeiro, v. 5, n. 2, p. 219-230, 2000.

CECCIM, Ricardo B.; FEUERWEKER, Laura C. M. Mudança na graduação das profissões de saúde sob o eixo da integralidade. Cadernos de Saúde Pública, Rio de Janeiro, v. 20, n.5, p. 1400-1410, set./out, 2004a.

CECCIM, Ricardo B.; FEUERWEKER, Laura C. M. O quadrilátero da formação para a área da saúde: ensino, gestão, atenção e controle social. Physis: Revista de Saúde Coletiva, Rio de Janeiro, v. 14, n. 1, p. 41-65, 2004b.

GIL, Antonio C. Como elaborar projetos de pesquisa. 4. ed., São Paulo: Atlas, 2002.

INSTITUTO Nacional de Estudos e Pesquisas Educacionais Anísio Teixeira (INEP). Sinaes: sistema nacional de avaliação da educação superior: da concepção à regulamentação. 4. ed. ampl. Brasília: INEP, 2007.

KRISTINA, Tri N.; MAJOOR, Gerard D.; VAN DER VLEUTEN, Cees P. M. Defining Generic Objectives for Community Based Education in Undergraduate Medical Programmes. Medical Education, Maestricht, v. 38, n. 5, p. 510-552, 2004.

LIMA, Marcos A. M. Autoavaliação e desenvolvimento institucional na educação superior: projeto aplicado em cursos de administração. Fortaleza: UFC, 2008.

LOBATO, Carolina P. Formação dos trabalhadores de saúde nas residências multiprofissionais em saúde da família: uma cartografia da dimensão política. 2010. 117 fls. Dissertação (Mestrado em Saúde Coletiva) - Universidade Estadual de Londrina, Londrina, 2010.

MARTINS, Gilberto A. Estudo de caso: uma reflexão sobre a aplicabilidade em pesquisas no Brasil. RCO: Revista de Contabilidade e Organizações, São Paulo, v. 2, n. 2, p. 8-18 jan./abr. 2008.

MARTINS JUNIOR, Tomaz et al. A residência multiprofissional em saúde da família de Sobral, Ceará. Sanare, Ceará v. 7, n. 2, p. 23-30, jul./dez. 2008.

MINAYO, Maria C. S. O desafio do conhecimento: pesquisa qualitativa em Saúde. 11. ed., São Paulo: Hucitec, 2008.

MORIN, Edgar. Os sete saberes necessários à educação do futuro. São Paulo: Cortez, 2000.

NÓBREGA, Silvia M. N.; THERRIEN, Jacques. Trabalhos científicos e o estado da questão: reflexões teórico-metodológicas. Revista EStudos em Avaliação Educacional, São Paulo, v. 15, n. 30, jul. /dez. 2004.

OLIVEIRA, Cathana F. A residência multiprofissional em saúde como possibilidade de formação de profissionais para o Sistema Único de Saúde. 2009. 105 f. Dissertação (Mestrado em Psicologia Social) - Pontifícia Universidade Católica do Rio Grande do Sul, Porto Alegre, 2009.

PARENTE, José R. F.; DIAS, Maria S. A.; CHAGAS, Maristela I. O. A trajetória da residência multiprofissional em saúde da família de Sobral. In: Ministério da Saúde (Org.). Residência multiprofissional em saúde: experiências, avanços e desafios. Brasília: Ministério da Saúde, v. 1, p. 81-96, 2006. 
PARENTE, José R. F. Preceptoria e tutoria na residência multiprofissional em saúde da família. Sanare, Sobral, v. 7, n. 2, jul./dez., 2008.

SANTOS, Fernanda A. Análise crítica dos projetos politico-pedagógicos de dois programas de residência multiprofissional em saúde da família. 2010. 104f. Dissertação (Mestrado em Ciências na área de Saúde Pública) - Fundação Oswaldo Cruz, Escola Nacional de Saúde Pública, Rio de Janeiro, 2010.

SCHAEDLER, Lucia I. Por um plano estético da avaliação nas residências multiprofissionais: construindo abordagens avaliativas SUS-implicadas. 2010. 184f. Tese (Doutorado em Educação) - Universidade Federal do Rio Grande de Sul, Porto Alegre, 2010.
STRUCHINER, Miriam; RICCIARDI, Regina M. V.; VETROMILLE, Vanise P. O painel de especialistas no processo de apreciação analítica de sistemas hipermídia para o ensino de graduação. CONGRESSO RIBIE, 4. Brasília, 1998. Disponível em: <http://sm.dei.uc. pt/ribie/docfiles/txt200342421216170.PDF>. Acesso em: 10 fev. 2012.

YIN, Robert K. Estudo de caso: planejamento e métodos. 2. ed. Porto Alegre: Bookman, 2001.

Recebido em 16/06/2014

Aprovado em 17/12/2014 